\title{
LA CONSAGRACIÓN CRISTIANA: BAUTISMAL Y ESPECÍFICA
}

DOI: https://doi.org/10.52039/seminarios.v61i213.187

Hablar de consagración es hablar de un concepto esencial para entender el evangelio y el ser cristiano. Etimológicamente significa «dedicar o apartar algo para Dios». Toda la vida de Jesús se puede leer desde esta perspectiva y se comprende que la vida del cristiano está dedicada a Dios, consagrada a la Trinidad, desde el bautismo. Jesús en la oración sacerdotal dice de sus discípulos que «no son del mundo, como tampoco yo soy del mundo» (Jn 17, 14) y no lo dice para constituir con ellos una élite de privilegiados porque no le pide al Padre que los retire del mundo, sino que los guarde del maligno para que se santifiquen en la verdad y enviarlos al mundo como testigos suyos (cf. 17, 15-18). Y concluye: «por ellos yo me santifico a mí mismo, para que también ellos sean santificados en la verdad» (v. 19). Jesús pide al Padre que preserve a los discípulos de la influencia mundo (en sentido joánico negativo) para enviarlos de nuevo al mundo (en sentido positivo) como testigos de la verdad del amor de Dios.

En este trabajo se intenta una aproximación al tema de la consagración desde la comprensión de la vida cristiana como vida consagrada a Dios por el bautismo. Para una visión más amplia de la realidad de la consagración en todos los aspectos de la vivencia del cristiano se busca la fundamentación desde el acercamiento antropológico-teológico de la teología del cuerpo, con el fin de entender la centralidad del concepto de consagración para una recta comprensión de la vida cristiana en todas sus facetas y peculiaridades. Desde esta visión de conjunto se aborda -en un paso posterior- las formas específicas de consagración a Dios en la Iglesia.

\section{SER CRISTIANO ES CONFIGURARSE CON CRISTO}

El punto de partida es la llamada de todo cristiano a conformarse con Cristo: se es cristiano en la medida en que se reproduce en uno mismo los misterios de Cristo. La primera realidad teológica es que el Hijo de Dios en su encarnación ha

* Nació en Buñol (Valencia) en 1963. Es miembro de la Fraternidad Misionera Verbum Dei y sacerdote desde 1993. Doctor in utroque iure. Director del Fondo Nueva Evangelización de la Conferencia Episcopal Española. 
asumido una personalidad humana que implica la posesión de un cuerpo, con el que se ha ofrecido a Dios como «sacerdote, víctima y altar».

Por eso, al entrar él en el mundo dice: Tú no quisiste sacrificios ni ofrendas, pero me formaste un cuerpo; no aceptaste holocaustos ni víctimas expiatorias. Entonces yo dije: He aquí que vengo -pues así está escrito en el comienzo del libro acerca de mí- para hacer, joh Dios!, tu voluntad. Primero dice: Tú no quisiste sacrificios ni ofrendas, ni holocaustos, ni víctimas expiatorias, que se ofrecen según la ley. Después añade: He aquí que vengo para hacer tu voluntad. Niega lo primero, para afirmar lo segundo. Y conforme a esa voluntad todos quedamos santificados por la oblación del cuerpo de Jesucristo, hecha una vez para siempre (Heb 10, 5-10).

La configuración del cristiano con Cristo significa que debe reproducir esta entrega a Dios que Jesucristo ha realizado de sí, hasta la ofrenda de su cuerpo en la cruz. El cristiano realiza así el culto en espíritu y verdad (cf. Jn 4, 24) que inaugura Cristo en su persona y que todo discípulo suyo está llamado a vivir:

Os exhorto, pues, hermanos, por la misericordia de Dios, a que presentéis vuestros cuerpos como sacrificio vivo, santo, agradable a Dios; este es vuestro culto espiritual. Y no os amoldéis a este mundo, sino transformaos por la renovación de la mente, para que sepáis discernir cuál es la voluntad de Dios, qué es lo bueno, lo que le agrada, lo perfecto (Rom 12, 1-2).

El concepto teológico que el Concilio Vaticano II ha utilizado para explicitar esta dimensión esencial de la vida cristiana es el de la participación en el sacerdocio de Cristo (LG 10). La vocación de cada cristiano a la entrega total de sí a Dios y a los demás se describe en los términos del sacerdocio de Cristo y la llamada a vivirlo que recibe todo cristiano por el bautismo:

Cristo Señor, Pontífice tomado de entre los hombres (cf. Heb 5, 1-5), de su nuevo pueblo «hizo... un reino y sacerdotes para Dios, su Padre» (Ap 1, 6; cf. 5, 9-10). Los bautizados, en efecto, son consagrados por la regeneración y la unción del Espíritu Santo como casa espiritual y sacerdocio santo, para que, por medio de toda obra del hombre cristiano, ofrezcan sacrificios espirituales y anuncien el poder de Aquel que los llamó de las tinieblas a su admirable luz (cf. 1 Pe 2, 4-10). Por ello todos los discípulos de Cristo, perseverando en la oración y alabando juntos a Dios (cf. Hch $2,42-47$ ), ofrézcanse a sí mismos como hostia viva, santa y grata a Dios (cf. Rom $12,1)$ y den testimonio por doquiera de Cristo, y a quienes lo pidan, den también razón de la esperanza de la vida eterna que hay en ellos (cf. $1 \mathrm{Pe} 3,15$ ).

Aunque la interpretación de los textos incluye el ofrecimiento de sí mismo en la totalidad psicosomática del ser humano, sin embargo, se puede caer en una lectura reductiva de los mismos, de tipo espiritualista y olvidando la dimensión corpórea de la entrega. Además la referencia al sacerdocio implica explicitar también -como hace el parágrafo siguiente de este texto conciliar- la relación entre el sacerdocio común de todo bautizado y el ministerial. 


\section{EL SIGNIFICADO ESPONSAL DEL CUERPO HUMANO}

Es mérito de san Juan Pablo II el haber desarrollo una teología específica del cuerpo humano que fundamenta en la realidad antropológica de la persona humana la vocación a una entrega total a Dios y a los demás ${ }^{1}$. De la doble consideración, por una parte, de la unidad de cuerpo y alma del ser humano y, por otra, de la diversidad sexual de varón y mujer, el Papa extrae consecuencias de profundo calado, ya que hacen ver la universal llamada de toda persona humana -y con mayor motivo del cristiano- a darse a los demás. Desde aquí es posible comprender de manera unitaria las diferentes maneras del don de sí en la tradición cristiana y, por ende, el significado y el valor de la consagración específica a Dios.

Teológicamente, san Juan Pablo II, en las numerosas catequesis que hizo sobre el sacramento del matrimonio, la familia, la virginidad y el celibato apostólico, desarrolla el significado del cuerpo humano como una verdadera y propia teología del cuerpo humano. Muy en síntesis, en la carta apostólica Mulieris dignitatem (n. 7) Juan Pablo II expone la teología del cuerpo desde el punto de partida de considerar la imagen y semejanza de Dios en el hombre.

El santo Papa expone que la imagen y semejanza del hombre con Dios está en «el carácter personal del ser humano», es decir, «criatura racional y libre, capaz de conocerlo [a Dios] y amarlo». Por eso mismo «el hombre no puede existir «solo» (cf. Gn 2, 18)» sino en relación con otra persona humana; la dualidad sexual indica que «se trata de una relación recíproca, del varón con la mujer y de la mujer con el varón». A esta relación entre el varón y la mujer el Papa le llama «unidad de los dos» e implica una llamada a vivir la comunión de amor, de manera que en ella dice que «esta «unidad de los dos», que es signo de la comunión interpersonal, indica que en la creación del hombre se da también una cierta semejanza con la comunión divina ('communio')».

La consecuencia más importante es que de esta realidad teológica, que constituye el «principio» de la vida humana, se desprende la vocación y la tarea propia de todo ser humano, que en el Nuevo Testamento desemboca en el mandamiento supremo del amor. La verdad antropológica acerca de la imagen y semejanza del hombre recuerda el Papa Juan Pablo II que el Concilio Vaticano II la expresó diciendo: «El Señor, cuando ruega al Padre que 'todos sean uno, como nosotros también somos uno' (Jn 17, 21-22), abriendo perspectivas cerradas a la razón humana, sugiere una cierta semejanza entre la unión de las personas divinas y la unión de los hijos de Dios en la verdad y en la caridad. Esta semejanza demuestra que el hombre, única criatura terrestre a la que Dios ha amado por sí misma, no puede encontrar su propia plenitud si no es en la entrega sincera de sí mismo

1. La bibliografía sobre el tema es muy abundante, aquí a modo de indicación se invita a leer B. Castilla de Cortázar Larrea, «Varón y mujer en la 'teología del cuerpo' de Karol Wojtyla», en J. M. Burgos (ed.), La filosofía personalista de Karol Wojtyla, Madrid 2007, 277-287. 
a los demás». De modo que la persona humana sólo puede realizarse de manera auténtica en la medida en que su vivir es una «entrega sincera de sí misma a los demás». Y añade el Papa «el modelo de esta interpretación de la persona es Dios mismo como Trinidad, como comunión de Personas. Decir que el hombre ha sido creado a imagen y semejanza de este Dios quiere decir también que el hombre está llamado a existir «para» los demás, a convertirse en un don».

Ciertamente en el contexto del texto del Génesis «el matrimonio es la dimensión primera y, en cierto sentido, fundamental de esta llamada» a la comunión de las personas, «pero no es la única». La realidad que permanece inmutable es que toda persona humana está llamada a una entrega total de su ser y el modelo bíblico de realización de la imagen y semejanza de Dios es el matrimonio. De ahí que el Papa hable del «carácter esponsal de la relación entre las personas» que cada una desarrolla según su propia peculiaridad y que en la tradición cristiana son el matrimonio o consagración a Dios en la virginidad o el celibato.

\section{JESÚS, EL ESPOSO POR EXCELENCIA}

La máxima revelación del carácter esponsal del cuerpo se halla implícita en la misma realidad de la encarnación del Hijo de Dios. Por ella se ha realizado la unión de lo divino y lo humano. En el Antiguo Testamento se alude con frecuencia a cómo Dios -representado como el novio o el esposo- busca la unión con su pueblo -representado como la novia o la esposa-. Pues bien, esta imagen simbólica del Antiguo Testamento, en el Nuevo deja de ser una mera imagen y se convierte en la realidad de Dios que por nosotros se hace hombre.

De hecho, a la pregunta sobre por qué sus discípulos no ayunan, Jesús responde que: «¿Es que pueden guardar luto los amigos del esposo, mientras el esposo está con ellos? Llegarán días en que les arrebatarán al esposo, y entonces ayunarán» (Mt 9, 15). Jesús, presentándose a sí mismo como el esposo y su presencia como un banquete de bodas, se revela como aquel que lleva a su plena realización la revelación del Antiguo Testamento del amor fiel y celoso de Dios por su pueblo. También Juan el Bautista se refiere a Jesús como el novio para manifestar lo propio de la misión de Cristo, a diferencia de la de los profetas e incluso la suya: «El que tiene la esposa es el esposo; en cambio, el amigo del esposo, que asiste y lo oye, se alegra con la voz del esposo; pues esta alegría mía está colmada» (Jn 3, 29).

Si la revelación bíblica en el Antiguo Testamento muestra el carácter esponsal del cuerpo humano, el Nuevo Testamento va mucho más allá, porque además de confirmar esta revelación la subraya de manera especial: Cristo es el Esposo por excelencia, que se ha entregado para unirse a su Esposa, la Iglesia.

De ahí que -ciñéndose a la vertiente cristológica- haya que hacer notar que el fundamento teológico de toda consagración está en que Jesús es el Esposo por excelencia y el cristiano para identificarse con Cristo debe imitarle en la entrega 
total y esponsal de sí a los demás. Dice Pablo: «Cristo amó a su Iglesia: Él se entregó a sí mismo por ella, para consagrarla, purificándola con el baño del agua y la palabra, y para presentársela gloriosa, sin mancha ni arruga ni nada semejante, sino santa e inmaculada» (Ef 5, 25-27) y lo pone como modelo del amor conyugal. Se entiende que éste es el modelo de toda entrega de sí a los demás, del amor cristiano por excelencia, el amor «más grande», pues «nadie tiene amor más grande que el que da la vida por sus amigos» (Jn 15, 13); es el amor que Jesús propone a sus discípulos: «os he dado ejemplo para que lo que yo he hecho con vosotros lo hagáis también vosotros» (Jn 13,15) y que los caracteriza como tales (cf. 13,35 ) ya que es lo que Jesús les manda: «Este es mi mandamiento: que os améis unos a otros como yo os he amado» $(15,12)$.

Según G. Martelet ${ }^{2}$, se ha descuidado demasiado el título cristológico de «Esposo»; para él, Jesús «el Esposo por excelencia» y «el Maestro y el Señor cuando se trata de amar a otro como a su propia carne». Aunque él lo propone como el fundamento de la teología del sacramento del matrimonio, no cabe duda que supone una importante aportación teológica para comprender el significado de la existencia psicosomática del ser humano en este mundo en la dualidad sexual. Este desarrollo teológico, por la referencia a la creación del hombre en el Génesis y a Adán y Eva y las referencias paulinas al «segundo Adán» (1 Cor $15,47)$, establece un puente y un fecundo diálogo entre la teología de la creación y de la redención. En particular, muestra cómo la llamada al don de sí mismo está profundamente inscrita en la naturaleza humana y cómo en Jesucristo el cristiano puede llevar a su máxima realización esta vocación universal de todo hombre. De hecho, Juan Pablo II en la exhortación apostólica Familiaris consortio usa el título de Jesucristo-Esposo de la Iglesia para explicar la esencia del sacramento del matrimonio y la inserción del vínculo conyugal entre el varón y la mujer en la realidad sacramental de la Iglesia (n. 13).

La teología del cuerpo y del significado esponsal del cuerpo se ha desarrollado en íntima conexión con la teología del sacramento del matrimonio. Su radio de acción, sin embargo, es más amplio. Reconocer el significado intrínseco del cuerpo como creado para la donación total de la persona es una importante aportación a la teología que rebasa el ámbito en que ha nacido ${ }^{3}$. En particular -en cuanto al tema de este trabajo- tiene la virtualidad de mostrar que la consagración es ciertamente un don de Dios, pero que tiene un fuerte fundamento antropológico que en el cristiano viene reforzado por el bautismo.

El cristiano por el bautismo se configura con Jesús, el Esposo de la Iglesia, por lo que su vida está destinada a reproducir la unión de lo divino y de lo humano por medio de la entrega total de su ser -incluido el propio cuerpo- sea por

2. «Dieciséis Tesis» de G. Martelet aprobadas «in forma generica» por la Comisión teológica internacional, en CTI, Doctrina católica sobre el matrimonio, 4 (1977).

3. Cf. también, por ejemplo, C. Álvarez, Teología del cuerpo y Eucaristía, Madrid 2010. 
medio del sacramento del matrimonio, sea en la consagración específica a Dios en la virginidad o el celibato. En la entrega personal de cada cristiano, personal y comunitaria, la Iglesia ofrece el mundo a Dios en respuesta al amor de Dios que le ha entregado a su Hijo, en espera de la consumación escatológica de las bodas del cordero (cf. Ap 19, 7).

\section{LOS MODOS CRISTIANOS DEL DON DE Sí}

La ventaja de esta presentación teológica de la persona humana es poner claramente de manifiesto que todo hombre está llamado al don de sí mismo a los demás. Es la base de partida común para comprender la realidad antropológica, moral y espiritual del ser humano. Las formas en que se especifica ulteriormente pueden ser muy diversas. En la tradición cristiana, el don de sí mismo que el cristiano hace a Dios y a los demás se hace en los estados de vida cristianos del matrimonio o de la virginidad o celibato.

El punto de partida es considerar el matrimonio como una entrega mutua y total de los esposos. Por eso sirve de paradigma para comprender -en base a la confirmación de la revelación bíblica del libro del Génesis de este dato antropológico- la realidad de la persona: «La mujer no dispone de su cuerpo, sino el marido; de igual modo, tampoco el marido dispone de su propio cuerpo, sino la mujer» $(1$ Cor 7 , 4). Por este motivo el Concilio Vaticano II habla del matrimonio como una "cuasi-consagración», poniendo de manifiesto que los esposos se deben el uno al otro, formando una comunidad de vida y amor, o la «unidad de los dos» de que habla Juan Pablo II.

La realidad de la comunión personal del matrimonio es la que hace comprender también que la virginidad y el celibato no tienen sentido en sí mismo -como mera ascesis personal-, ellas tienen sentido para una entrega en cuerpo y alma a Dios, para hacer una ofrenda esponsal del cuerpo a aquel que se lo ha dado a la persona humana para amar. No es un guardarse el cuerpo para sí mismo, sino que es para darlo y darse en él a Dios y a los demás. Como recuerda Juan Pablo II en la misma Familiaris consortio en el número 16:

La virginidad y el celibato por el Reino de Dios no sólo no contradicen la dignidad del matrimonio, sino que la presuponen y la confirman. El matrimonio y la virginidad son dos modos de expresar y de vivir el único Misterio de la Alianza de Dios con su pueblo. Cuando no se estima el matrimonio, no puede existir tampoco la virginidad consagrada; cuando la sexualidad humana no se considera un gran valor donado por el Creador, pierde significado la renuncia por el Reino de los cielos.

Esta manera de abordar la consagración desde la teología del cuerpo arroja luz sobre la relación que hay entre la vocación a una consagración específica a Dios y la vocación al matrimonio. El cristiano tiene ante sí dos posibilidades abiertas para vivir la vocación universal a la santidad. En una perspectiva me- 
ramente humana ambas posibilidades se excluyen recíprocamente, en la perspectiva cristiana se complementan en el Cuerpo de Cristo que es la Iglesia, Esposa de Jesucristo: la vocación matrimonial es sacramento de la unión de Cristo y la Iglesia; en la vocación a la consagración por la virginidad «el hombre está a la espera, incluso corporalmente, de las bodas escatológicas de Cristo con la Iglesia, dándose totalmente a la Iglesia con la esperanza de que Cristo se dé a ésta en la plena verdad de la vida eterna. La persona virgen anticipa así en su carne el mundo nuevo de la resurrección futura» (FC 16c).

La ventaja pastoral de esta presentación de la vida cristiana es el enfoque desde la perspectiva profundamente vocacional. Dios está en permanente diálogo con su criatura para mostrarle su amor, para guiarle y manifestarle su voluntad, es decir, la manera en que le puede responder al amor que recibe para bien suyo y de todos los demás. Ningún servicio, ministerio, estado, en la Iglesia -por humilde que sea- es mera opción personal humana, es siempre fruto de una llamada de Dios y de la subsiguiente respuesta libre de la persona. Esta visión también saca a la vocación a la consagración específica a Dios del régimen de la excepcionalidad, que tan peligroso es: si la vocación al sacerdocio o la vida consagrada es algo excepcional, además de crear dicotomías entre los miembros del pueblo de Dios, puede situar a la misma persona llamada en una posición psicológica delicada, porque entonces se puede pensar en la vocación como algo estático y en la respuesta no como fruto de un proceso de discernimiento continuo de la voluntad de Dios, sino de un esfuerzo de la voluntad humana por ser fiel a una llamada, que al final aparece lejana en el tiempo. La dualidad básica de vocaciones en la Iglesia -matrimonio y virginidad o celibato- hacen comprender que, más allá de la disposición básica a acoger una de ellas, cada una encierra a su vez otras múltiples vocaciones subordinadas que son ulteriores especificaciones de las mismas y que el cristiano debe estar siempre en proceso continuo de discernimiento para percibir las llamadas de Dios a lo largo de su vida.

\section{Consagración ESPECÍFICA A DIOS}

Todo cristiano por el bautismo es consagrado a Dios por Cristo en el Espíritu Santo para ofrecerse a Dios y ser testigos de Cristo con toda su vida. Esta es una vocación común a todos los bautizados que se realiza por medio del carácter sacramental del bautismo y su perfeccionamiento se logra con el carácter del sacramento de la confirmación. Esto significa que el cristiano está llamado a configurarse con Cristo ontológica y existencialmente. De esta manera la Iglesia es un pueblo sacerdotal puesto que participa de la consagración de Cristo. Todo cristiano ha sido introducido en la vida divina y por su pertenencia a Cristo tiene la misión de llevar a Dios, junto con los demás bautizados, todas las realidades humanas, de realizar la unión de lo divino y lo humano que se realizó en Cristo y en él se consumará escatológicamente. 
Consagración -como ya se ha indicado- etimológicamente significa poner aparte para Dios. El hecho de que el ser humano sea imagen y semejanza de Dios es la razón por la cual toda acción de Dios en el hombre tiende a que esta imagen se manifieste de una manera u otra en el individuo y en el pueblo escogido de Dios. La historia de la salvación es testigo de cómo todas las intervenciones de Dios son para elegir y para capacitar a alguien de su pueblo para destinarlo a una tarea peculiar. En la plenitud de los tiempos (cf. Gal 4, 4), aparece Jesús, el Mesías escogido por Dios y enviado a anunciar la Buena noticia del reino de Dios para fundar el nuevo pueblo de Dios. La pertenencia a este pueblo no es en razón de la raza, la sangre o los vínculos humanos, sino por una elección de Dios y la llamada a recibir el bautismo. De esta manera todo cristiano ha recibido la gracia de la elección y del destino a la misión de la Iglesia en este mundo; ya no se pertenece: ha sido consagrado. «Ninguno de nosotros vive para sí mismo y ninguno muere para sí mismo. Si vivimos, vivimos para el Señor; si morimos, morimos para el Señor; así que ya vivamos ya muramos, somos del Señor. Pues para esto murió y resucitó Cristo: para ser Señor de muertos y vivos» (Rom 14, 7-9).

La forma en que de manera simbólico-sacramental expresa en la comunión de la Iglesia la común vocación de los cristianos a vivir la consagración bautismal es a través del signo de aquellos cristianos que reciben una vocación específica de consagración a Dios. Tradicionalmente las formas cristianas de vivir la consagración específica a Dios suponen asumir el vivir en la virginidad o el celibato, como signo de que la humanidad entera está llamada a la realidad escatológica de la vida eterna. Las dos vocaciones que para ello existen en la Iglesia son el ministerio ordenado y la vida consagrada ${ }^{4}$. Estas formas de consagración dan visibilidad a dos dimensiones de la entrega total a Dios: en el servicio ministerial al pueblo de Dios y en la plasmación existencial del modo de vida de Jesús pobre, casto y obediente.

\section{El sacramento del orden}

El ministerio ordenado ha sido instituido por Cristo para el servicio de todo el pueblo de Dios (cf. LG 18; Catecismo de la Iglesia Católica (CEC 874). Puesto que es un servicio en orden a la salvación (y no meramente estructural u organizativo) «está intrínsecamente ligado a la naturaleza sacramental» (CEC 876).

4. Dada la brevedad de este trabajo y su carácter de síntesis, la atención se centra en las formas institucionalizadas en la Iglesia por lo que no se considera las modalidades que han aparecido de consagración privada de fieles (aunque sea en el marco de asociaciones de fieles). Obviamente desde la perspectiva adoptada permite comprender el significado y la importancia de la consagración privada (o sea, no en el seno de un instituto de vida consagrada reconocido y erigido por la autoridad eclesiástica) de los fieles, pero incluirla llevaría demasiado lejos en el modesto propósito que aquí se persigue. Además, tampoco se puede abordar el desarrollo teológico para la comprensión de por qué es posible la recepción del sacramento del orden en el grado del diaconado (en la Iglesia católica latina) por parte de varones casados. 
Son «ministros de la gracia, autorizados y habilitados por parte de Cristo» (CEC 875). Gracias al sacramento del Orden «la misión confiada por Cristo a sus Apóstoles sigue siendo ejercida en la Iglesia hasta el fin de los tiempos: es, pues, el sacramento del ministerio apostólico» (CEC 1536). Este sacramento comprende tres grados: el episcopado, el presbiterado y el diaconado; por medio de él los bautizados ordenados reciben de Cristo «los obispos y los presbíteros reciben la misión y la facultad (el «poder sagrado») de actuar in persona Christi Capitis, los diáconos las fuerzas para servir al pueblo de Dios en la «diaconía» de la liturgia, de la palabra y de la caridad, en comunión con el obispo y su presbiterio» (CEC 875).

La naturaleza sacramental de la ordenación impide que se entienda como una cuestión de organización social. La referencia original es a los «órdenes» romanos, o sea, los cuerpos que estructuraban la sociedad y el gobierno. La Iglesia ha recogido la denominación, pero ha mudado su esencia, dándole carácter teológico. Y así, la ordenación no es un mero rito de integración en un cuerpo, sino que es un acto sacramental (cf. CEC 1538). La ordenación sacramental "confiere un don del Espíritu Santo que permite ejercer un 'poder sagrado' (sacra potestas) (cf. LG 10) que sólo puede venir de Cristo, a través de su Iglesia» (ibíd.).

Por el peculiar ministerio que se confiere y ya que es esencial para la naturaleza de la Iglesia y el ejercicio de su misión, la ordenación tiene una dimensión de una fuerte trascendencia: el bautizado ordenado ya no se posee a sí mismo, ni puede dedicarse a ninguna otra labor humana, porque ha sido consagrado para el servicio a Jesucristo en la Iglesia. "La ordenación también es llamada consecratio porque es un 'poner aparte' y un 'investir' por Cristo mismo para su Iglesia. La 'imposición de manos' del obispo, con la oración consecratoria, constituye el signo visible de esta consagración» (ibíd.).

Además del carácter indeleble (cf. CEC 1581ss.), en las personas ordenadas el sacramento produce el efecto de la gracia del Espíritu para «ser configurado Cristo, Sacerdote, Maestro y Pastor, de quien el ordenado es constituido ministro» (CEC 1585). Es, pues, necesario que el ordenado oriente su vida según un peculiar acuerdo con su estado (cf. CEC 1589). El derecho canónico se encarga de determinar con precisión el estatuto jurídico del estado de vida de los ministros sagrados (o clérigos, en terminología canónica) en la Iglesia (cc. 232-293).

\section{La vida consagrada}

Junto a la manera de vivir la consagración a Dios en el ministerio ordenado, surgió muy pronto en la Iglesia la manera de vivir de aquellos bautizados que, sin ser necesariamente ordenados y, por tanto, sin una dedicación litúrgico-sacramental al pueblo de Dios, asumían una forma de vivir de mayor dedicación a Dios por la oración, el estilo de vida según el evangelio interpretado con más exigencia, el lugar donde vivían (fuera de las poblaciones o en clausura), el servicio 
de la caridad y a los pobres, etc. A lo largo de la historia de la Iglesia este modo de vida eclesial ha asumido diversas modalidades y denominaciones. Actualmente se le denomina «vida consagrada» con la intencionalidad de poner claramente de manifiesto que el objetivo que siempre ha perseguido es vivir y mostrar una dedicación total y exclusiva a Dios. Por este motivo el Concilio Vaticano II afirma que «el estado de vida que consiste en la profesión de los consejos evangélicos, aunque no pertenezca a la estructura de la Iglesia, pertenece, sin embargo, sin discusión a su vida y a su santidad» (LG 44; cf. CEC 914).

La vida según la propuesta que Jesús hace en el evangelio es para cualquier cristiano y es mérito del Vaticano II resaltar la llamada universal de todo el pueblo de Dios a la santidad. Por una especial vocación divina, algunos fieles son llamados a vivir los consejos evangélicos, practicando «la castidad en el celibato por el Reino, la pobreza y la obediencia» (CEC 915) y ello de manera pública, es decir haciendo profesión de ellos, obligándose libremente a vivir el estado de vida reconocido por la Iglesia como «vida consagrada» (cf. LG 42-43; PC 1).

La consagración por la profesión pública de los consejos evangélicos se hace por la respuesta a una especial vocación y un don del Espíritu ${ }^{5}$ por la que el cristiano se entrega totalmente a Dios. Es un «voto» (H. U. von Balthasar): una entrega total, que se especifica en los consejos evangélicos de castidad, pobreza y obediencia. La Iglesia acoge el don de la vida consagrada en su seno y le da el carácter de testimonio público y de estado de vida en ella, regido por las normas del derecho canónico (Código de Derecho Canónico (CIC, Libro II, Parte Tercera). El $\mathrm{CIC}$ resume la esencia del estado de la vida consagrada en la Iglesia en el c. 573. De manera muy sintética se pueden distinguir como elementos teológicos: a) la dedicación total a Dios; b) el seguimiento de Cristo más de cerca bajo la acción del Espíritu Santo; c) la profesión de los consejos evangélicos; d) la unión con la Iglesia por y para la perfección de la caridad; e) la significación escatológica. Los elementos jurídicos, en cambio, son: a) la estabilidad de la forma de vida; b) la erección canónica de las distintas formas; c) la opción libre y vocacional por dicha forma de parte de las personas; d) los votos u otros vínculos, con los que se viven los consejos; e) la observancia de las leyes propias de cada Instituto. El conjunto de todos los elementos teológicos y jurídicos es lo que configura el estado de la vida consagrada tal y como lo reconoce y promueve la Iglesia.

Por razón del reconocimiento como estado de vida eclesial, la consagración a Dios en un instituto de vida consagrada se realiza por medio de un acto litúrgico aprobado por la Iglesia. Pero este acto litúrgico no es un sacramento. Según VC 30 se trata de la «nueva y especial consagración» sobre la base de los sacramentos del bautismo, confirmación y orden. Es «una singular y fecunda profundización de la consagración bautismal», no una consecuencia necesaria

5. Cf. J. Castellano, Especificidad de la vida consagrada, vida de especial consagración, Tabor 1 (2007) 44-51. 
del mismo y se corresponde con un don específico del Espíritu Santo. La vida consagrada asume el testimonio público del amor de Dios y del prójimo con un servicio carismático de gran importancia en la Iglesia. En cuanto modo de vivir que adelanta en este mundo el reino escatológico no puede ser sacramento, porque el rito litúrgico se queda en el signo y no puede producir el efecto, ya que no es de este mundo; la anticipación de la realidad futura trascendente puede ser anticipada en el tiempo sólo como profecía.

Se ve así que cuando hablamos de consagración específica hay dos formas principales: el del ministerio sagrado y el de la vida consagrada. En realidad, son usos diferentes del mismo término «consagración», ya que la causa y los efectos son distintos. Sin embargo, la consagración sacramental de los ministros conlleva un determinado estilo de vida que manifieste su dedicación a Dios y a la Iglesia: la austeridad de vida, el celibato de los sacerdotes y la obediencia pastoral. Por otro lado, las personas consagradas no lo son el mismo sentido que los ministros, ya que no es un sacramento, sino que asumen un peculiar estilo de vida en testimonio de pobreza, castidad y obediencia y servicio cualificado al pueblo de Dios; pero la Iglesia reconoce que la vida consagrada pertenece a su vida y santidad y la acoge con un rito litúrgico e instituye un estado de vida canónico, que regula con leyes peculiares. Así pues, el resultado es que aunque la causa eficiente de la consagración sea diferente -sacramental en un caso, vocacional y carismática en el otro- se da una gran semejanza de ambas vocaciones de los célibes en la Iglesia. Esto es fruto de la unidad profunda que hay entre ellas, como signo de la centralidad de la consagración para la vida y la misión de la Iglesia.

\section{CONCLUSIÓN}

De manera sumaria se ha visto en este trabajo que toda persona humana está llamada a hacer de la totalidad de su vida un don a los demás. Esta verdad antropológica está inscrita en el significado esponsal del propio cuerpo humano. En el caso del cristiano, esta realidad tiene mucha mayor consistencia, ya que el cristiano por el bautismo se incorpora a Cristo y le hace formar parte de la Iglesia, pueblo sacerdotal, cuerpo y esposa de Cristo.

Una primera consecuencia es que hay que poner cada vez más de manifiesto que la vida en general y la vida cristiana de modo particularmente fuerte sólo debe ser entendida como vocación y específicamente vocación al don de sí mismo a Dios y a los demás. No se puede seguir pensando en la Iglesia que la vocación sea algo excepcional o un privilegio de unos pocos en la Iglesia. Un enfoque netamente vocacional de la pastoral -en todos sus ámbitos- ayudará a que los bautizados en su vida cristiana respondan con mayor libertad, generosidad y alegría a la gracia que recibe abundantemente de Dios a través de la Iglesia en la Palabra y los sacramentos, tal y como pide el papa Francisco. 
Además, las vocaciones a una especial consagración son el signo que Dios ha dado a la Iglesia para que toda ella viva como un pueblo de consagrados con la misión de conducir a toda la humanidad hacia Dios. Estas vocaciones son muy importantes en la Iglesia ya que recuerdan a todo cristiano la necesidad de vivir para Dios y la misión que ha encomendado a la Iglesia. Como recuerda el papa Francisco la mundanidad hace un tremendo daño a la Iglesia pues le aparta de su vocación esencial de conducir todas las realidades humanas hacia Dios. En la Iglesia las personas consagradas que viven una especial consagración animan con su testimonio y con su labor específica a que todo el pueblo de Dios realice la vocación universal a la santidad y a la misión evangelizadora de la Iglesia.

La consagración específica-sea ministerial sea en la vida consagrada- presta además un gran servicio a la Iglesia ya que su dedicación a distintas labores espirituales, apostólicas o misioneras hace que la misión de la Iglesia tenga mayor incidencia en la mundo. En cualquier caso la consagración no debe ser mirada nunca desde un punto de vista de su utilidad, reduciéndola a la eficacia práctica que pueda reportar a la Iglesia. Su función va mucho más allá: son el recuerdo y la actualización permanente en la Iglesia del ministerio de Cristo, Esposo de la Iglesia, que cuida de ella con amor solícito, se dedica a ella, para alimentar su vida y hacerla crecer en el Espíritu. 